\title{
Review \\ Odontogenic Maxillary Sinusitis: The Interface and Collaboration between Rhinologists and Dentists
}

\author{
Beeshman Saireuben Nandakumar ${ }^{1,2}$, Naomi Natasha Amalee Niles ${ }^{1,2}$ and Larry Hilton Kalish ${ }^{1,2,3, *}$ \\ 1 Department of Otolaryngology, Head and Neck Surgery, Concord Repatriation General Hospital, \\ Concord, NSW 2139, Australia; bnan3289@uni.sydney.edu.au (B.S.N.); \\ nnil8655@uni.sydney.edu.au (N.N.A.N.) \\ 2 Faculty of Medicine and Health, University of Sydney, Camperdown, NSW 2006, Australia \\ 3 Rhinology and Skull Base Research Group, St Vincent's Centre for Applied Medical Research, \\ University of New South Wales, Kensington, NSW 2056, Australia \\ * Correspondence: 1hkalish@mac.com
}

Citation: Nandakumar, B.S.; Niles, N.N.A.; Kalish, L.H. Odontogenic Maxillary Sinusitis: The Interface and Collaboration between Rhinologists and Dentists. J. Otorhinolaryngol. Hear. Balance Med. 2021, 2, 8. https:// doi.org/10.3390/ohbm2040008

Academic Editors: Ron Eliashar and Asaf Wilensky

Received: 19 October 2021

Accepted: 16 November 2021

Published: 27 November 2021

Publisher's Note: MDPI stays neutral with regard to jurisdictional claims in published maps and institutional affiliations.

Copyright: (c) 2021 by the authors. Licensee MDPI, Basel, Switzerland. This article is an open access article distributed under the terms and conditions of the Creative Commons Attribution (CC BY) license (https:/ / creativecommons.org/licenses/by/ $4.0 /)$.

\begin{abstract}
Odontogenic maxillary sinusitis (OMS) is an inflammatory condition affecting the paranasal sinuses and is commonly encountered by both Otorhinolaryngologists and Dentists. However, there is an ongoing debate regarding the best sequence of management. Clinicians are faced with the dilemma of first addressing either the affected tooth or the affected sinus. This paper provides a review of the current literature on the aetiology, presentation, and management of OMS, as well as our experience in managing this condition. Overall, the causative pathology of the patient's OMS, their symptoms, and the risk of surgery should drive decision making with regards to sequence of management.
\end{abstract}

Keywords: odontogenic; sinusitis; unilateral; maxillary; periapical; dentist; rhinologist

\section{Introduction}

Odontogenic maxillary sinusitis (OMS) is an inflammatory condition affecting the paranasal sinuses as a consequence of underlying dental pathology, trauma or instrumentation. It is encountered by both Otorhinolaryngologists and Dentists and is implicated in $5 \%$ to $40 \%$ of all cases of chronic maxillary sinusitis [1]. OMS most commonly occurs in the fifth to seventh decades of life, with a slight female predilection. It has seen a growing incidence in recent years, linked to a rise in dental procedures [2-6].

The paired maxillary sinuses lie within the maxillary bone and are bounded superiorly by the orbital floor, posteriorly by the anterior border of the pterygopalatine fossa and inferiorly by the alveolar process of the maxilla. The maxillary tooth roots commonly reach the floor of the maxillary sinus, providing a route for an infection to spread from the oral cavity into the maxillary sinus [3,7]. The maxillary sinus is lined by pseudostratified ciliated respiratory epithelium and drains via its superiorly located ostium into the infundibulum, through the hiatus semilunaris and into the middle meatus. An extension of inflammation from the maxillary sinus to the osteomeatal complex (OMC), the common drainage pathway of the anterior ethmoid and the maxillary and frontal sinuses, may lead to other sinuses becoming affected [8].

Anatomic variations that impair mucous drainage or narrow the OMC can predispose the development of sinusitis and treatment failure. The most common anatomical variant is the infraorbital ethmoid cell, which narrows the outflow tract and compromises the flow. The outflow tract is rarely compromised by concha bullosa or septal deviations except in extreme circumstances. The development of knowledge of the complex and variable anatomy of the sinuses and their drainage pathways is therefore imperative in the successful management of OMS [9]. For example, the degree of pneumatization of the maxillary sinuses can vary greatly between individuals. Hypoplasia is reported 
in $1-11 \%$ of the population, and may be related to congenital syndromes, trauma or iatrogenic injury [10]. Limited airflow within hypoplastic sinuses can impair mucociliary activity, which allows mucostasis and bacterial invasion to develop [11]. Other variants include the presence of accessory ostia, which is found in $20-50 \%$ of individuals. This is thought to be a consequence of impaired drainage from the primary ostium, due to chronic inflammation or other structural or pathological anomalies affecting the middle meatus. While accessory ostia can relieve maxillary sinus pressure in sinusitis, they can also result in the "recirculation syndrome", whereby mucous re-enters the sinus via the main ostium rather than following the normal drainage pathway, again predisposing the sinus to inflammation [10].

The purpose of this article is to provide a comprehensive review of the recent literature pertaining to the aetiology, clinical findings, diagnostic modalities and best sequence of management of OMS, allowing us to better understand the role of and interaction between the Otorhinolaryngologist and Dentist. A literature search was performed using the Medline, EMBASE, and EBMR databases. All of the full-text articles on OMS, pertaining to humans, written in English and published between 2001 and 2021 were included in the review. The search terms used were "odontogenic, dentigerous, cyst, radicular, keratocyst, periapical abscess and maxillary sinusitis". Of the 260 records obtained, 223 abstracts were assessed for eligibility for their inclusion after screening duplicates. Reports that included a single patient experience, orbital sequelae, and malignancy were excluded. Key article references were searched, resulting in 14 additional papers. Subsequently, 158 papers were included for consideration and 55 were cited in this paper. See Figure S1, which has been adapted following the PRISMA guidelines detailing search results and the excluded articles [12].

\section{Aetiology}

First described in the literature in 1943, Bauer demonstrated through post-mortem histopathological analysis that once odontogenic microbes reached the maxillary alveolar bone, they could spread via lymphovascular channels within the bone to reach the Schneiderian membrane lining the maxillary sinus [13]. The subsequent inflammation and oedema could impair drainage via the osteomeatal complex resulting in OMS. In the years since, a variety of odontogenic causes of maxillary sinusitis have been described, including iatrogenic, endodontic, and periodontic $[2,3,14-16]$.

\subsection{Iatrogenic}

Iatrogenic causes are the most common causes of OMS. In their systematic review, Lechien et al., determined that $65.7 \%$ of the 674 cases reviewed were iatrogenic [3]. Furthermore, in a meta-analysis of 770 patient cases Arias-Irimia et al. identified $55.97 \%$ of patient cases as being iatrogenic in origin [2]. Dento-alveolar surgery and its complications precipitate OMS by either an inadvertent compromise to the Schneiderian membrane through an oro-antral communication (OAC), or through the introduction of a foreign body such as dental implants or obturation material (Figure 1) [2,15-17]. Although an $\mathrm{OAC}$ may epithelialize to become an oro-antral fistula (OAF), this is not necessary for the transmission of microbes to the maxillary sinus. A sinus lift is a dento-alveolar procedure of increasing popularity that incurs a $23.5 \%$ weighted risk of OAC creation [18]. In this procedure, a deliberate osteotomy is made to the lateral maxillary wall to access and 'lift up' the Schneiderian membrane, to provide space for a bone graft. This exposes the bilaminar Schneiderian membrane to microbes within the oral cavity and may inadvertently result in an OAC, thereby precipitating OMS [15]. The implantation of foreign bodies such as dental implants or amalgam for obturation provide vectors for infection [19]. A dental amalgam containing zinc oxide, sulphur or calcium salts can accelerate fungal growth, especially in those who are immunocompromised [3]. The extraction of native teeth has also been implicated in the formation of an OAC at rates of $0.31 \%$ to $4.7 \%$, thereby promoting OMS [15]. 
(a)

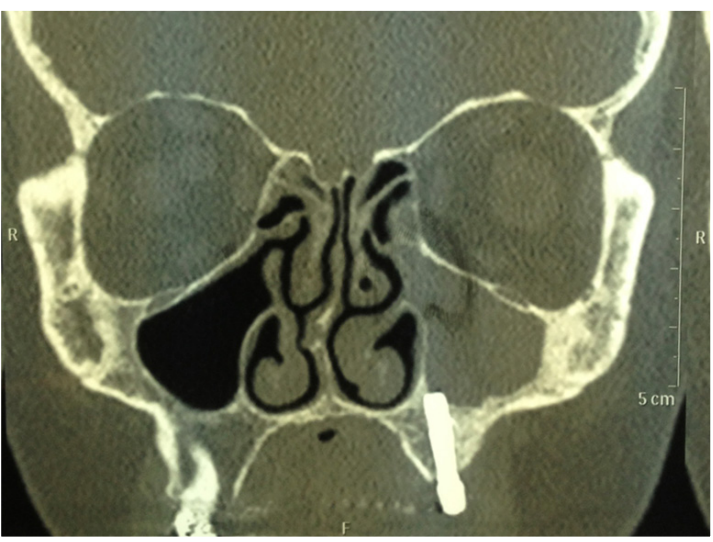

(c)

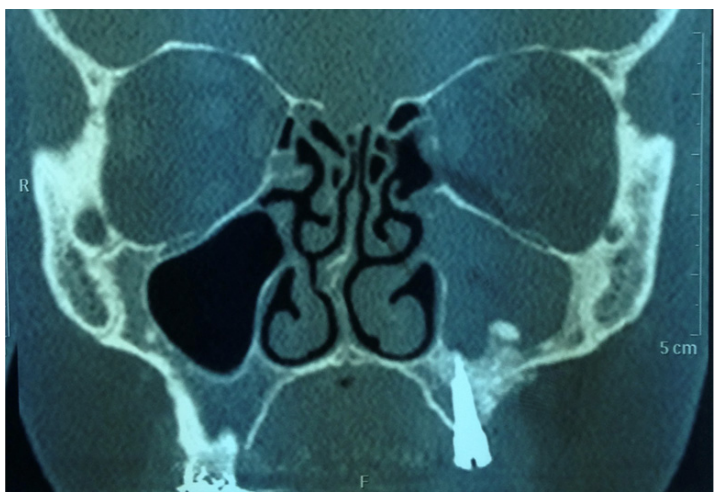

(b)

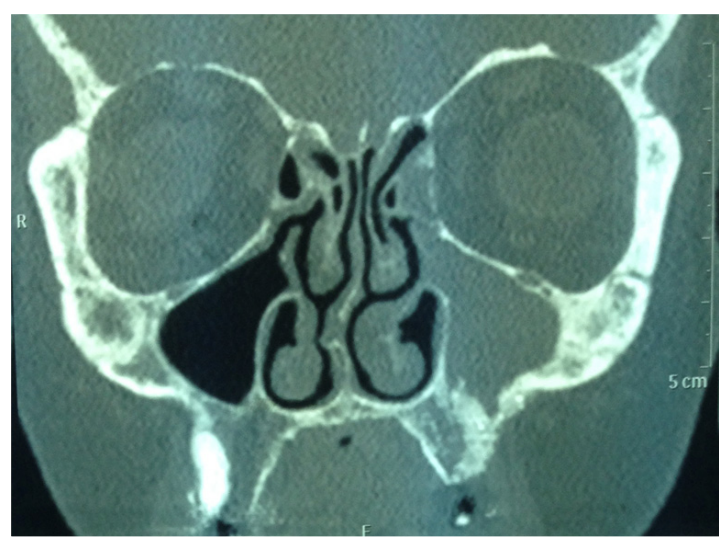

(d)

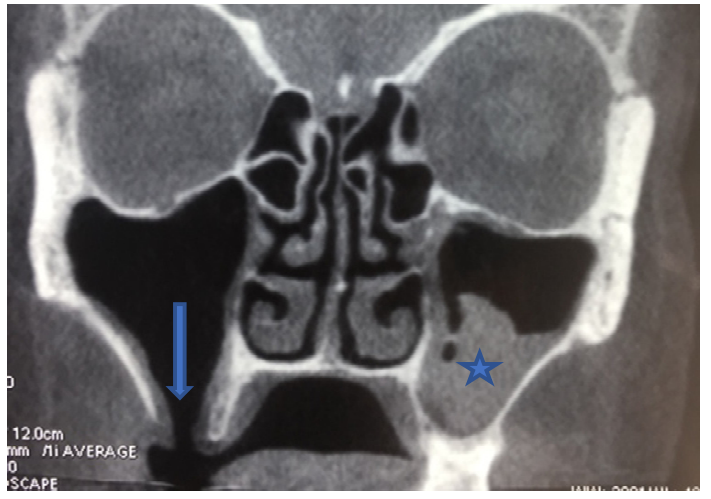

Figure 1. Computed tomography demonstrating iatrogenic left maxillary sinusitis secondary to (a) dental implant; (b) sinus lift; (c) sinus lift and dental implant and; (d) oro-antral fistula on the right (arrow) and evidence of a fungal ball and obstructed osteomeatal complex on the left (star).

\subsection{Endodontic and Periodontic Disease}

Endodontic and periodontic diseases include apical periodontal pathology (such as apical periodontitis with or without periapical lesions), odontogenic cysts, pulpal necrosis and root fracture (Figure 2) [14,16]. Periapical lesions refer to periapical cysts, abscesses, or granulomas [20]. The common developmental odontogenic cysts implicated in OMS include dentigerous cysts (Figure 3), whilst inflammatory odontogenic cysts associated with OMS include radicular cysts [21]. A periapical or endodontic infection occurs when oral bacteria accesses the vital pulp [15]. As it becomes immunologically shielded by the physical barrier of the tooth root, once an infection is within the vital pulp it can easily spread to the apical root causing periapical lesions which are in close proximity to the maxillary bone and sinus. Lechien et al., demonstrated that the upper molars, specifically the first and second molars, are most frequently implicated in OMS [3].

\subsection{Microbiology}

With regards to microbiology, the literature is unified in the polymicrobial nature of OMS $[1,4,16,22,23]$. Whilst anaerobic agents are more commonly found than their counterparts, there is less consensus in the literature regarding the primary causative organism in OMS [16]. In a recent retrospective study comparing cultures taken from 276 patients with chronic rhinosinusitis (CRS) or OMS, it was found that the common OMS microbes included a mixture of Fusobacterium species, Eikenella corrodens, and Streptococcus species [16]. Interestingly, there was no significant difference in the polymicrobial burden between OMS and CRS, however, Pseudomonas aeruginosa and Staphylococcus aureus, common pathogens in CRS, were less likely to be found in OMS [16]. Conversely, Zirk et al., found that Pseudomonas aeruginosa was significantly associated with migrated implants 
and obturation material in OMS [4]. The most frequent fungal infection, especially in apical periodontitis due to proximity to the maxilla, is Aspergillus species [24,25].

(a)

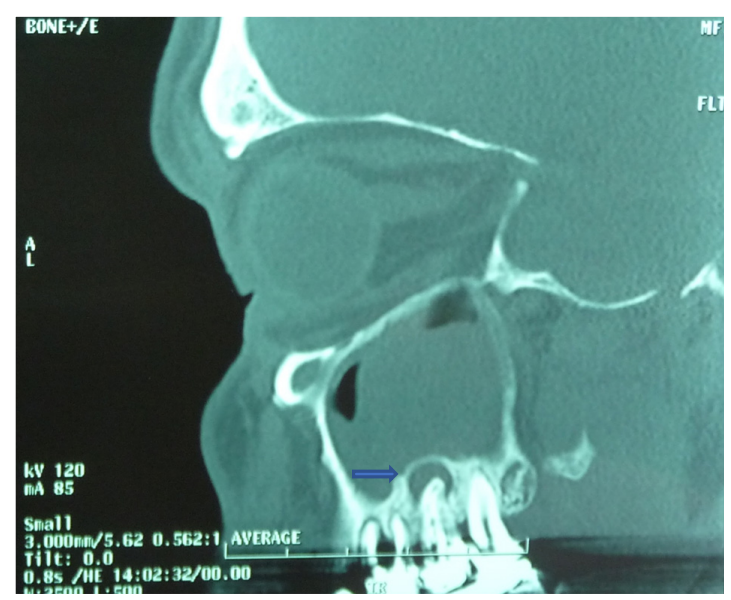

Figure 2. Computed tomography demonstrating maxillary sinusitis secondary to (a) periapical abscess on sagittal view (horizontal arrow) and; (b) periodontic disease on coronal view (vertical arrow).

(a)

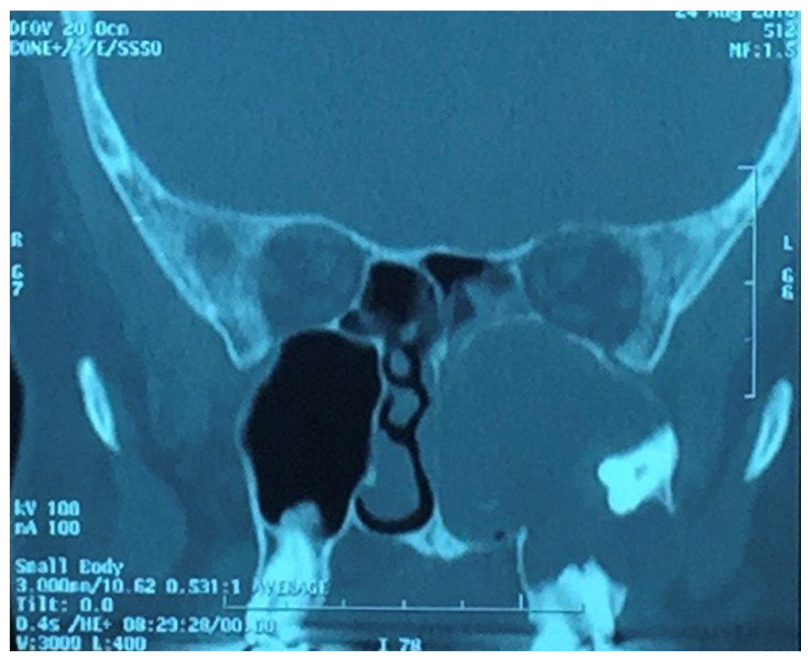

(b)

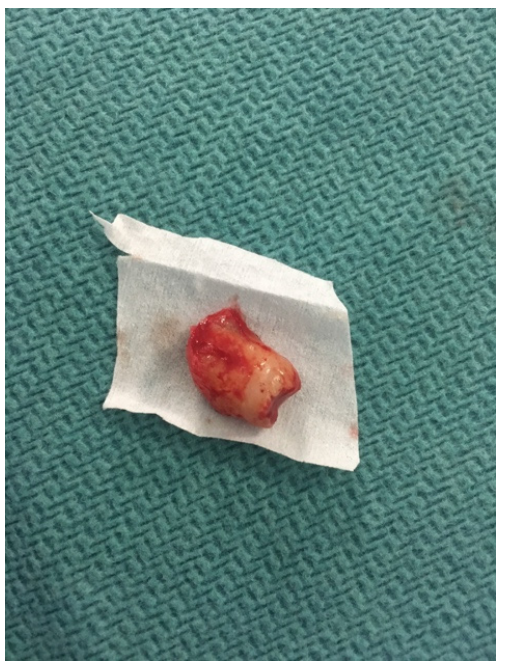

Figure 3. (a) Computed tomography demonstrating left maxillary sinusitis secondary to a dentigerous cyst, and; (b) tooth extracted from dentigerous cyst after Modified Medial Maxillectomy approach.

\section{Presentation}

Patients with OMS often complain of unilateral facial pain, pressure or nasal congestion, purulent anterior rhinorrhoea, post-nasal drip and cacosmia. For any sinus patient with unilateral symptoms, who describes a "foul smell", odontogenic causes of sinusitis are always high on the differential list. Dental pain is present in only one third of such patients $[26,27]$. Importantly, OMS may arise as a late complication of dental implants, thus a thorough history of both recent and distant dental procedures should be obtained $[26,28]$. The examination should include a thorough inspection of the patient's dentition, including the presence of implants and their condition, root fractures, $\mathrm{OAF}$, and the condition of the dental pulp. The most common finding on nasoendoscopy is the occurrence of unilateral purulent discharge from the middle meatus and inflammatory changes of the nasal mucosa (Figure 4) $[7,26]$.

Imaging plays a crucial role in diagnosis and in guiding management. Computed tomography (CT) of the paranasal sinuses is the gold standard for the evaluation of maxillary sinusitis, providing an excellent bone and soft tissue resolution [29]. Unilateral maxillary sinus opacification is the most common finding of OMS on CT, and is present in $70 \%$ to $100 \%$ of 
cases $[8,27,28,30-40]$. The presence of periapical lucencies is the most common indicator of an odontogenic source (Figure 5) [41]. It is important to note that dental pathology is often underreported by radiologists, with between $35 \%$ and $66 \%$ of dental disease missed on CT reports, necessitating the careful assessment of the maxillary dentition on CT by the clinician $[30,33,42]$. Though less sensitive, periapical radiography can be used as a tool to identify dental caries and periodontal disease [7]. Cone Beam CT (CBCT) scans are routinely used in many dental practices for both diagnostic purposes and when planning for implants. CBCT's undeniable advantage of multiplanar reconstruction has revolutionized implant dentistry; it allows visualization without the superimposition of structures [43]. It is the authors' opinion that most parameters are set to exclude the maxillary outflow tracts, therefore, when maxillary pathology is incidentally picked up, further management decisions are limited. An inclusion of the OMC would allow for better medical management options to be implemented.

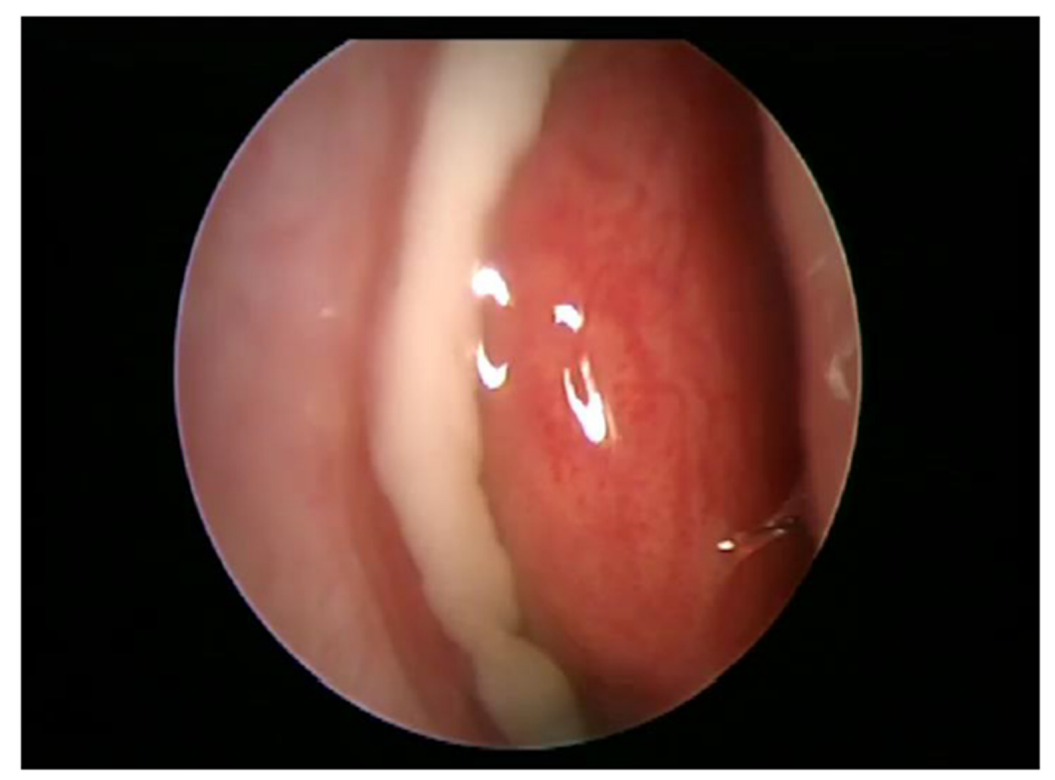

Figure 4. Nasoendoscopic view showing purulent discharge from the right middle meatus.

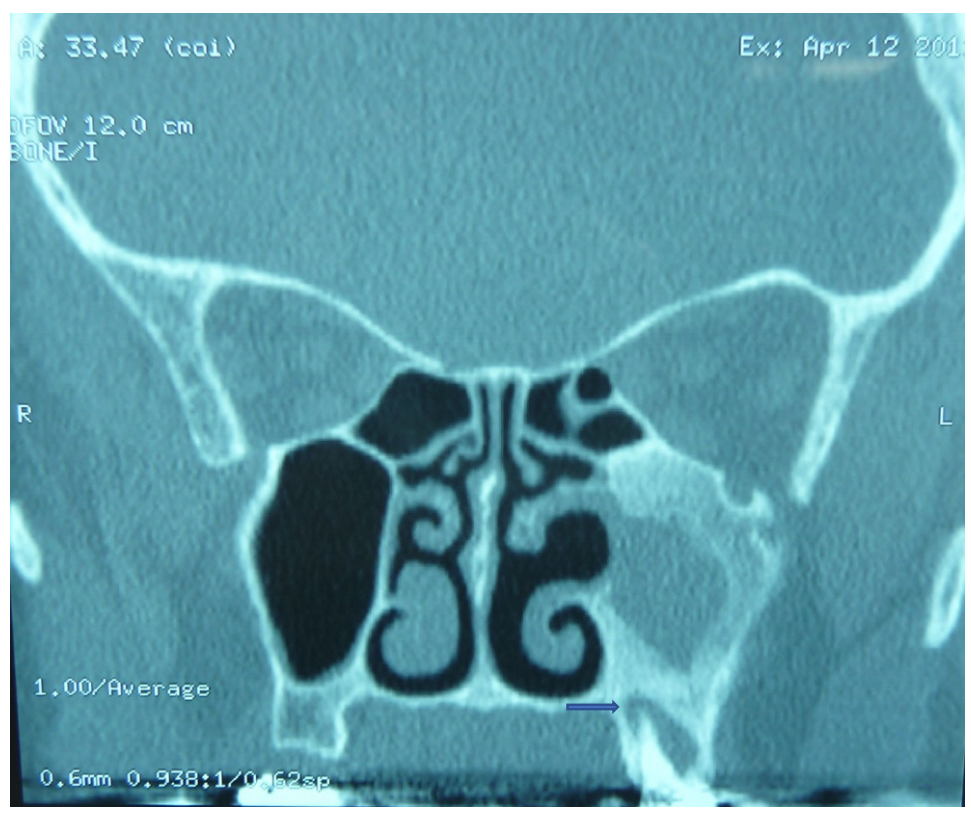

Figure 5. Computed tomography demonstrating left maxillary sinus opacification with surrounding hyperostosis secondary to a periapical abscess (horizontal arrow). 


\section{Management}

Cause directed management is crucial in OMS. Management options for OMS can be broadly divided into medical, dental, and surgical categories. In a retrospective analysis of cultures taken from 121 patients with OMS, Zirk et al. tested microbiological susceptibility to common antibiotics and determined that penicillin beta-lactamase inhibitor combinations (Piperacillin/Tazobactam 93\%, Amoxicillin/Sulbactam 80\%) and quinolones (Moxifloxacin $86.2 \%$ ) induced the highest rates of susceptibility [4].

Whilst antimicrobial therapy alone is not advocated for in treating most cases of OMS, it can be useful in temporary symptom alleviation $[14,36]$. The inflammation and obstruction of sinus outflow tracts result in persistent sinonasal symptoms, and the addition or sole use of topical anti-inflammatories in the form of intranasal corticosteroids is often necessary to treat symptoms and OMS [44]. Furthermore, no studies have directly assessed the efficacy of antimicrobial therapy alone in treating OMS, with many case series focusing on dental and surgical intervention after the failure of antimicrobial-only therapy [36]. Thus, dental and surgical options for definitive treatment are necessary in combination with supportive antimicrobials and/or topical anti-inflammatories.

Dental treatment centers on root canal therapy or tooth extraction to obtain source control over endodontic infections [15]. Root canal therapy involves the removal of the neurovascular contents of a tooth (dental pulp) before it is replaced with obturation material. However, if this fails, tooth extraction may be required. When considering dental treatment alone, Longhini and Ferguson's 21 patient case series found 90\% resolution [27]. In addition to their small patient population, they did not consider sinonasal symptoms or the follow up duration when analyzing successful resolution. Larger retrospective studies, which include 43 and 39 patients, have shown lower success rates at $52 \%$ and $51 \%$ respectively $[45,46]$. In a more recent prospective study of 11 patients that accounted for sinonasal symptoms and nasoendoscopic findings, only 36\% experienced resolution of OMS within 2.5 months of dental treatment alone [36].

Surgical options in the management of OMS must consider the access required and the sinuses involved. Surgery can be categorized as either endoscopic or open and is performed primarily by Otorhinolaryngologists. In circumstances that require greater access, the Caldwell-Luc approach has been used historically [28]. This was followed by a transoral approach through the anterior wall of the maxillary sinus or via the canine fossa $[4,34,47]$. However, with technical advances, trans-nasal endoscopic sinus surgery (ESS) has become the main form of treatment for maxillary sinusitis, including for that of odontogenic origin [14,48]. A multitude of endoscopic techniques have been used in the treatment of odontogenic disease, including maxillary antrostomy, "mega-antrostomy," and modified medial maxillectomy (MMA). A systemic review of case reports showed these were effective and safe options [49]. In the authors' experience, with MMA we are able to access and manage a variety of dental pathologies endonasally, including the repair of select OAF using vascularised floor mucosal flaps.

In our analysis of $556 \mathrm{MMA}$ cases reviewed for a variety of pathologies including 17 that were odontogenic in origin, we demonstrated very low morbidity, with $1.3 \%$ of patients experiencing post operative bleeding, no orbital or lacrimal injuries, no cosmetic changes or permanent paraesthesia, and a mucostasis rate of $9.4 \%$ (non-functioning sinus with sumping), none of which occurred in the odontogenic group. We demonstrated a significant improvement in the SNOT-22 score and a revision rate of 3.4\%, again with none of the odontogenic cases requiring revision. (Figure 6) (Current research unpublished). 


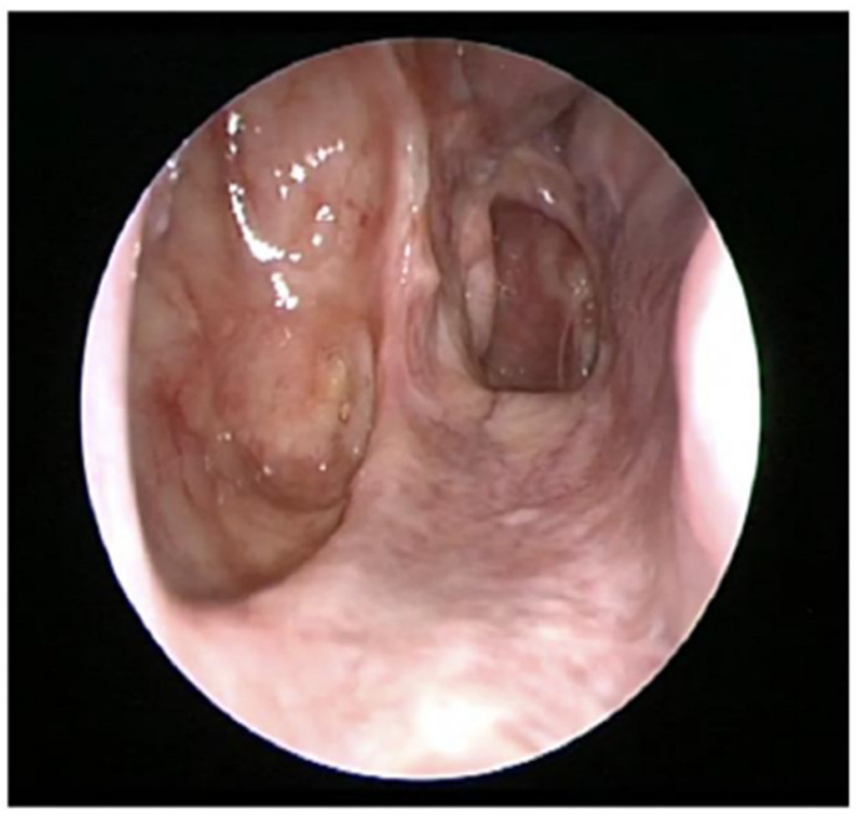

(a)

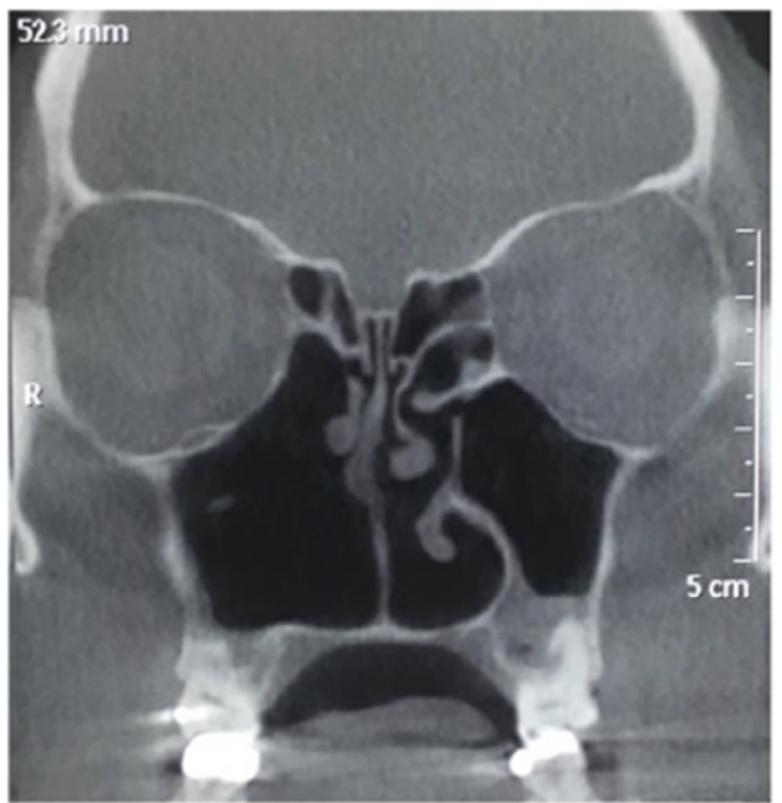

(b)

Figure 6. (a) Nasoendoscopic view and (b) computed tomography demonstrating excellent access for disease monitoring post right medial maxillectomy.

Kim et al., found a 100\% success rate for ESS which included antrostomies of the involved sinuses with the removal of inflammatory mucosa, when performed alone after the failure of antibiotics [50]. Whilst foreign bodies were removed and OAFs were closed with local flaps in their case series, dental implants that may have protruded into the maxillary sinus were not removed. Of the 19 patients with iatrogenic dental implant OMS that Kim et al. followed prospectively for 2 years, 4 were managed conservatively with antibiotics whilst the remaining 15 progressed to ESS after the failure of conservative therapy [50]. Contrastingly, both Chen et al., and Doud Galli et al., found lower success rates of $69 \%$ and $57 \%$ respectively for dental implant related OMS [39,51]. In both studies, those patients that did not respond to ESS found resolution with dental intervention. In Doud Galli et al.'s 14-patient study, ESS constituted a middle meatal maxillary antrostomy with the routine removal of visibly extruded dental implants [51]. However, in Chen et al.'s 18 patient study, an antrostomy of the involved sinuses was performed without the removal of dental implants during ESS [39].

Combined dental and ESS management consistently demonstrates high success rates of $90-100 \%$ in the management of OMS refractory to medical management [5,20,34,36,38,40,45-47,52,53]. Furthermore, Saibene et al., proposed a treatment protocol which combines dental and surgical input with a $97.6 \%$ success [53]. Treatment combinations of ESS, dental implant removal and $\mathrm{OAC}$ repair were determined by dividing patients into three groups based on whether they had pre-implant, implant-related, or dental disease [53].

Although there is a consensus that a combination of dental and surgical inputs is required in the workup and management of OMS refractory to medical therapy, the ideal sequence of which expert should first administer treatment is still not clear [14,53]. Previous studies suggest that primary dental intervention should be followed by ESS only if necessary $[3,15,54]$. Contrastingly, other multi-disciplinary groups have reached a consensus that primary ESS be performed in OMS, with those refractory to surgical management necessitating secondary dental intervention [14]. There is an absence of highlevel evidence to suggest either is correct, and this remains an avenue for future research. 


\section{Recommendations}

It is our opinion that odontogenic sinusitis, which does not respond to appropriate medical management, warrants effective endoscopic surgical intervention. The rationale is that this can safely relieve the sinus outflow obstruction and reduce the risk of OAF. Simply removing the offending tooth does not always settle the underlying sinus inflammation. Furthermore, by using MMA approaches, the dental disease can be partially or totally addressed in the same surgery. Close inspection of the maxillary outflow tract and OMC is critical in determining whether to proceed with ESS or dental intervention. In patients with patent OMC post medical management, it is reasonable to proceed with dental interventions. However, some patients with partially or completely obstructed OMC secondary to mucosal inflammation may have pathologies such as fungal debri or polyps, or anatomical restrictions such as infraorbital ethmoid cells, large concha bullosa or lateralized uncinates. In this situation, addressing the sinuses first is a better option in our opinion (Figure 7).

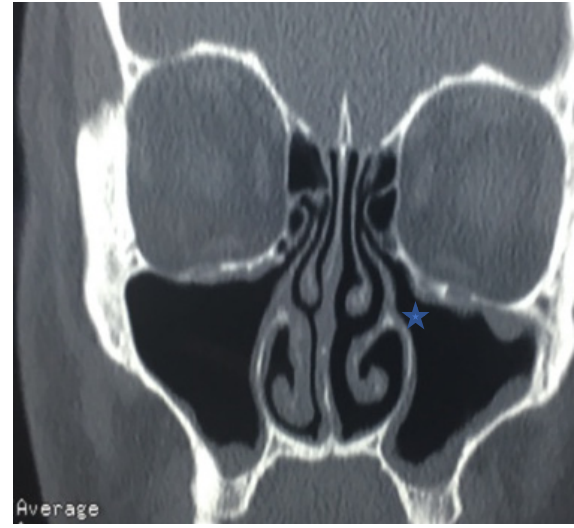

(a)

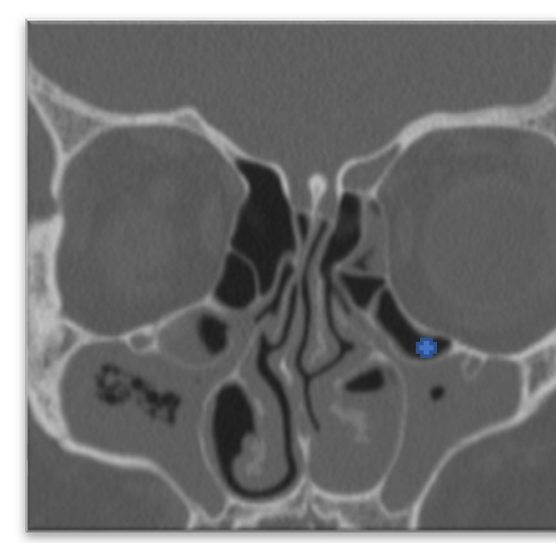

(b)

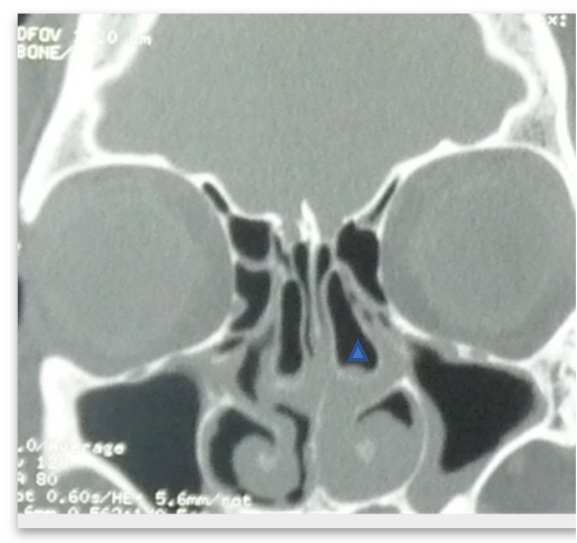

(c)

Figure 7. (a) Minor mucosal changes but patent OMC (star) (b) infraorbital cells blocking OMC (cross) (c) Concha Bullosa blocking OMC (triangle).

\section{Conclusions}

It is evident that a shared-care model be applied to OMS wherein the key stakeholders are Dentists, Otorhinolaryngologists, and the patient. The causative pathology of the patient's OMS, their symptoms, and the risk of surgery should guide decision making with regards to the sequence of management. Future research should focus on producing high-level evidence to better guide the sequence of specialist management for the treatment of OMS.

Supplementary Materials: The following are available online at https: / www.mdpi.com/article/ 10.3390/ohbm2040008/s1, Figure S1: PRISMA guidelines detailing search results and the excluded articles for this paper.

Author Contributions: Conceptualization, B.S.N., N.N.A.N., L.H.K.; literature search B.S.N. and N.N.A.N.; writing—original draft preparation, B.S.N., N.N.A.N. and L.H.K.; writing-review and editing, B.S.N., N.N.A.N. and L.H.K.; supervision, L.H.K.; project administration, L.H.K. All authors have read and agreed to the published version of the manuscript.

Funding: This research received no external funding.

Institutional Review Board Statement: Not applicable.

Informed Consent Statement: Not applicable. 
Data Availability Statement: Data regarding the 556 Modified Maxillary Antrostomy cases we report our experience with is currently unpublished. For any enquiries, please contact A/Prof Larry Kalish (corresponding author).

Conflicts of Interest: The authors declare no conflict of interest.

\section{References}

1. Puglisi, S.; Privitera, S.; Maiolino, L.; Serra, A.; Garotta, M.; Blandino, G.; Speciale, A. Bacteriological findings and antimicrobial resistance in odontogenic and non-odontogenic chronic maxillary sinusitis. J. Med. Microbiol. 2011, 60, 1353-1359. [CrossRef]

2. Arias-Irimia, O.; Barona Dorado, C.; Santos Marino, J.; Martinez Rodriguez, N.; Martinez Gonzalez, J.M. Meta-analisis of the etiology of odontogenic maxillary sinusitis. Medicina Oral Patología Oral y Cirugía Buccal 2010, 15, e70-e73.

3. Lechien, J.R.; Filleul, O.; De Araujo, P.C.; Hsieh, J.W.; Chantrain, G.; Saussez, S. Chronic Maxillary Rhinosinusitis of Dental Origin: A Systematic Review of 674 Patient Cases. Int. J. Otolaryngol. 2014, 2014, 465173. [CrossRef]

4. Zirk, M.; Dreiseidler, T.; Pohl, M.; Rothamel, D.; Buller, J.; Peters, F.; Zöller, J.E.; Kreppel, M. Odontogenic sinusitis maxillaris: A retrospective study of 121 cases with surgical intervention. J. Cranio-Maxillofac. Surg. 2017, 45, 520-525. [CrossRef] [PubMed]

5. Lopatin, A.S.; Sysolyatin, S.P.; Sysolyatin, P.G.; Melnikov, M.N. Chronic maxillary sinusitis of dental origin: Is external surgical approach mandatory? Laryngoscope 2002, 112, 1056-1059. [CrossRef]

6. Hoskison, E.; Daniel, M.; E Rowson, J.; Jones, N.S. Evidence of an increase in the incidence of odontogenic sinusitis over the last decade in the UK. J. Laryngol. Otol. 2011, 126, 43-46. [CrossRef]

7. Little, R.E.; Long, C.M.; Loehrl, T.A.; Poetker, D.M. Odontogenic sinusitis: A review of the current literature. Laryngoscope 2018, 3, 110-114. [CrossRef]

8. Saibene, A.M.; Pipolo, G.C.; Lozza, P.; Maccari, A.; Portaleone, S.M.; Scotti, A.; Borloni, R.; Messina, F.; Di Pasquale, D.; Felisati, G. Redefining boundaries in odontogenic sinusitis: A retrospective evaluation of extramaxillary involvement in 315 patients. Int. Forum Allergy Rhinol. 2014, 4, 1020-1023. [CrossRef] [PubMed]

9. Reddy, U.D.M.A.; Dev, B. Pictorial essay: Anatomical variations of paranasal sinuses on multidetector computed tomographyHow does it help FESS surgeons? Indian J. Radiol. Imaging 2012, 22, 317-324. [CrossRef] [PubMed]

10. Papadopoulou, A.-M.; Chrysikos, D.; Samolis, A.; Tsakotos, G.; Troupis, T. Anatomical Variations of the Nasal Cavities and Paranasal Sinuses: A Systematic Review. Cureus 2021, 13, e12727. [CrossRef]

11. Akay, G.; Yaman, D.; Karadag, O.; Güngör, K. Evaluation of the Relationship of Dimensions of Maxillary Sinus Drainage System with Anatomical Variations and Sinusopathy: Cone-Beam Computed Tomography Findings. Med. Princ. Pract. 2019, $29,354-363$. [CrossRef] [PubMed]

12. Page, M.J.; McKenzie, J.E.; Bossuyt, P.M.; Boutron, I.; Hoffmann, T.C.; Mulrow, C.D.; Shamseer, L.; Tetzlaff, J.M.; Akl, E.A.; Brennan, S.E.; et al. The PRISMA 2020 statement: An updated guideline for reporting systematic reviews. BMJ 2021, 372, n71. [CrossRef] [PubMed]

13. Bauer, W.H. Maxillary sinusitis of dental origin. Am. J. Orthod. Oral Surg. 1943, 29, B133-B151. [CrossRef]

14. Craig, J.R.; Dds, R.W.T.; Aghaloo, T.L.; Pokorny, A.T.; Gray, S.T.; Mattos, J.L.; Poetker, D.M. Management of odontogenic sinusitis: Multidisciplinary consensus statement. Int. Forum Allergy Rhinol. 2020, 10, 901-912. [CrossRef] [PubMed]

15. Psillas, G.; Papaioannou, D.; Petsali, S.; Dimas, G.G.; Constantinidis, J. Odontogenic maxillary sinusitis: A comprehensive review. J. Dent. Sci. 2020, 16, 474-481. [CrossRef]

16. Yassin-Kassab, A.; Bhargava, P.; Tibbetts, R.J.; Griggs, Z.H.; Peterson, E.I.; Craig, J.R. Comparison of bacterial maxillary sinus culture between odontogenic sinusitis and chronic rhinosinusitis. Int. Forum Allergy Rhinol. 2021, 11, 40-47. [CrossRef]

17. Galli, M.; DE Soccio, G.; Cialente, F.; Candelori, F.; Federici, F.R.; De Vincentiis, M.; Minni, A. Chronic maxillary sinusitis of dental origin and oroantral fistula: The results of combined surgical approach in an Italian university hospital. Bosn. J. Basic Med. Sci. 2020, 20, 524-530. [CrossRef] [PubMed]

18. Al-Dajani, M. Incidence, Risk Factors, and Complications of Schneiderian Membrane Perforation in Sinus Lift Surgery: A MetaAnalysis. Implant Dent. 2016, 25, 409-415. [CrossRef]

19. Newsome, H.A.; Poetker, D.M. Odontogenic Sinusitis: Current Concepts in Diagnosis and Treatment. Immunol. Allergy Clin. N. Am. 2020, 40, 361-369. [CrossRef] [PubMed]

20. Akinyamoju, A.O.; Gbadebo, S.O.; Adeyemi, B.F. PERIAPICAL LESIONS OF THE JAWS: A REVIEW OF 104 CASES IN IBADAN. Ann. Ib. Postgrad. Med. 2014, 12, 115-119. [PubMed]

21. Rajendra Santosh, A.B. Odontogenic Cysts. Dent. Clin. N. Am. 2020, 64, 105-119. [CrossRef] [PubMed]

22. Brook, I. Microbiology of Acute and Chronic Maxillary Sinusitis Associated with an Odontogenic Origin. Laryngoscope 2005, 115, 823-825. [CrossRef] [PubMed]

23. Saibene, A.M.; Vassena, C.; Pipolo, C.; Trimboli, M.; De Vecchi, E.; Felisati, G.; Drago, L. Odontogenic and rhinogenic chronic sinusitis: A modern microbiological comparison. Int. Forum Allergy Rhinol. 2015, 6, 41-45. [CrossRef] [PubMed]

24. Costa, F.; Emanuelli, E.; Robiony, M.; Zerman, N.; Polini, F.; Politi, M. Endoscopic Surgical Treatment of Chronic Maxillary Sinusitis of Dental Origin. J. Oral Maxillofac. Surg. 2007, 65, 223-228. [CrossRef] [PubMed]

25. Gomes, C.; Pinto, L.C.C.; Victor, F.L.; Da Silva, E.A.B.; Ribeiro, A.A.; Sarquis, M.I.D.M.; Camões, I.C.G. Aspergillus in endodontic infection near the maxillary sinus. Braz. J. Otorhinolaryngol. 2015, 81, 527-532. [CrossRef] 
26. Elwany, S.; A Ibrahim, A.; A Hussein, W.K.; Medra, A.M.; Elwany, N. Ten-year experience with multidisciplinary diagnosis and treatment of odontogenic sinusitis. J. Laryngol. Otol. 2021, 135, 987-992. [CrossRef] [PubMed]

27. Longhini, A.B.; Ferguson, B.J. Clinical aspects of odontogenic maxillary sinusitis: A case series. Int. Forum Allergy Rhinol. 2011, 1, 409-415. [CrossRef] [PubMed]

28. Lee, K.C.; Lee, S.J. Clinical Features and Treatments of Odontogenic Sinusitis. Yonsei Med. J. 2010, 51, 932-937. [CrossRef]

29. Workman, A.D.; Granquist, E.J.; Adappa, N.D. Odontogenic sinusitis: Developments in diagnosis, microbiology, and treatment. Curr. Opin. Otolaryngol. Head Neck Surg. 2018, 26, 27-33. [CrossRef] [PubMed]

30. Wang, K.L.; Nichols, B.G.; Poetker, D.M.; Loehrl, T.A. Odontogenic sinusitis: A case series studying diagnosis and management. Int. Forum Allergy Rhinol. 2015, 5, 597-601. [CrossRef] [PubMed]

31. Matsumoto, Y.; Ikeda, T.; Yokoi, H.; Kohno, N. Association between odontogenic infections and unilateral sinus opacification. Auris Nasus Larynx 2015, 42, 288-293. [CrossRef] [PubMed]

32. Turfe, Z.; Ahmad, A.; Peterson, E.I.; Craig, J.R. Odontogenic sinusitis is a common cause of unilateral sinus disease with maxillary sinus opacification. Int. Forum Allergy Rhinol. 2019, 9, 1515-1520. [CrossRef] [PubMed]

33. Pokorny, A.; Tataryn, R. Clinical and radiologic findings in a case series of maxillary sinusitis of dental origin. Int. Forum Allergy Rhinol. 2013, 3, 973-979. [CrossRef]

34. Costa, F.; Emanuelli, E.; Franz, L.; Tel, A.; Robiony, M. Single-step surgical treatment of odontogenic maxillary sinusitis: A retrospective study of 98 cases. J. Cranio-Maxillofacial Surg. 2019, 47, 1249-1254. [CrossRef] [PubMed]

35. Akiyama, K.; Nakai, Y.; Samukawa, Y.; Miyake, M.; Hoshikawa, H. Assessment of Simultaneous Surgery for Odontogenic Sinusitis: Endoscopic Sinus Surgery with Endoscopic Apicoectomy. J. Craniofacial Surg. 2019, 30, 239-243. [CrossRef] [PubMed]

36. Craig, J.R.; McHugh, C.I.; Do, Z.H.G.; Peterson, E.I. Optimal timing of endoscopic sinus surgery for odontogenic sinusitis. Laryngoscope 2019, 129, 1976-1983. [CrossRef] [PubMed]

37. Gaudin, R.A.; Hoehle, L.P.; Smeets, R.; Heiland, M.; Caradonna, D.S.; Gray, S.T.; Sedaghat, A.R. Impact of odontogenic chronic rhinosinusitis on general health-related quality of life. Eur. Arch. Oto-Rhino-Laryngol. 2018, 275, 1477-1482. [CrossRef] [PubMed]

38. Ungar, O.J.; Yafit, D.; Kleinman, S.; Raiser, V.; Safadi, A. Odontogenic sinusitis involving the frontal sinus: Is middle meatal antrostomy enough? Eur. Arch. Oto-Rhino-Laryngol. 2018, 275, 2291-2295. [CrossRef] [PubMed]

39. Chen, Y.-W.; Huang, C.-C.; Chang, P.-H.; Chen, C.-W.; Wu, C.-C.; Fu, C.-H.; Lee, T.-J. The Characteristics and New Treatment Paradigm of Dental Implant-related Chronic Rhinosinusitis. Am. J. Rhinol. Allergy 2013, 27, 237-244. [CrossRef] [PubMed]

40. Crovetto-Martinez, R.; Martin-Arregui, F.; Zabala-Lopez-De-Maturana, A.; Tudela-Cabello, K.; La Torre, M.C.-D. Frequency of the odontogenic maxillary sinusitis extended to the anterior ethmoid sinus and response to surgical treatment. Medicina Oral Patología Oral y Cirugía Buccal 2014, 19, e409-e413. [CrossRef] [PubMed]

41. Mccarty, J.L.; David, R.M.; Lensing, S.Y.; Samant, R.S.; Kumar, M.; Van Hemert, R.L.; Angtuaco, E.J.; Fitzgerald, R.T. Root Cause Analysis: An Examination of Odontogenic Origins of Acute Maxillary Sinusitis in Both Immunocompetent \& Immunocompromised Patients. J. Comput. Assist. Tomogr. 2017, 41, 484-488. [CrossRef]

42. Turfe, Z. Odontogenic sinusitis is a common cause of unilateral maxillary sinus and middle meatal polypoid disease. Int. Forum Allergy Rhinol. 2019, 9, S97. [CrossRef] [PubMed]

43. Haiderali, Z. The role of CBCT in implant dentistry: Uses, benefits and limitations. Br. Dent. J. 2020, $228,560-561$.

44. Meltzer, E.O.; Bachert, C.; Staudinger, H. Treating acute rhinosinusitis: Comparing efficacy and safety of mometasone furoate nasal spray, amoxicillin, and placebo. J. Allergy Clin. Immunol. 2005, 116, 1289-1295. [CrossRef]

45. Mattos, J.L.; Ferguson, B.J.; Lee, S. Predictive factors in patients undergoing endoscopic sinus surgery for odontogenic sinusitis. Int. Forum Allergy Rhinol. 2016, 6, 697-700. [CrossRef] [PubMed]

46. Tomomatsu, N.; Uzawa, N.; Aragaki, T.; Harada, K. Aperture width of the osteomeatal complex as a predictor of successful treatment of odontogenic maxillary sinusitis. Int. J. Oral Maxillofac. Surg. 2014, 43, 1386-1390. [CrossRef] [PubMed]

47. Felisati, G.; Chiapasco, M.; Lozza, P.; Saibene, A.M.; Pipolo, G.C.; Zaniboni, M.; Biglioli, F.; Borloni, R. Sinonasal Complications Resulting from Dental Treatment: Outcome-Oriented Proposal of Classification and Surgical Protocol. Am. J. Rhinol. Allergy 2013, 27, e101-e106. [CrossRef] [PubMed]

48. Jacob, K.J.; George, S.; Preethi, S.; Arunraj, V.S. A Comparative Study Between Endoscopic Middle Meatal Antrostomy and Caldwell-Luc Surgery in the Treatment of Chronic Maxillary Sinusitis. Indian J. Otolaryngol. Head Neck Surg. 2011, 63, 214-219. [CrossRef] [PubMed]

49. Marino, M.J.; Luong, A.; Yao, W.C.; Citardi, M.J. Management of Odontogenic Cysts by Endonasal Endoscopic Techniques: A Systematic Review and Case Series. Am. J. Rhinol. Allergy 2018, 32, 40-45. [CrossRef] [PubMed]

50. Kim, S.J.; Park, J.S.; Kim, H.T.; Lee, C.H.; Park, Y.H.; Bae, J.H. Clinical features and treatment outcomes of dental implant-related paranasal sinusitis: A 2-year prospective observational study. Clin. Oral Implant. Res. 2015, 27, e100-e104. [CrossRef] [PubMed]

51. Galli, S.K.D.; Lebowitz, R.A.; Giacchi, R.J.; Glickman, R.; Jacobs, J.B. Chronic Sinusitis Complicating Sinus Lift Surgery. Am. J. Rhinol. 2001, 15, 181-186. [CrossRef] [PubMed]

52. Andric, M.; Saranovic, V.; Drazic, R.; Brkovic, B.; Todorovic, L. Functional endoscopic sinus surgery as an adjunctive treatment for closure of oroantral fistulae: A retrospective analysis. Oral Surg. Oral Med. Oral Pathol. Oral Radiol. Endodontol. 2010, 109, 510-516. [CrossRef] 
53. Saibene, A.M.; Collurà, F.; Pipolo, C.; Bulfamante, A.M.; Lozza, P.; Maccari, A.; Arnone, F.; Ghelma, F.; Allevi, F.; Biglioli, F.; et al. Odontogenic rhinosinusitis and sinonasal complications of dental disease or treatment: Prospective validation of a classification and treatment protocol. Eur. Arch. Oto-Rhino-Laryngol. 2018, 276, 401-406. [CrossRef] [PubMed]

54. Zhu, J.; Lin, W.; Yuan, W.; Chen, L. New Insight on Pathophysiology, Diagnosis, and Treatment of Odontogenic Maxillary Sinusitis. J. Nanomater. 2021, 2021, 9997180. [CrossRef] 